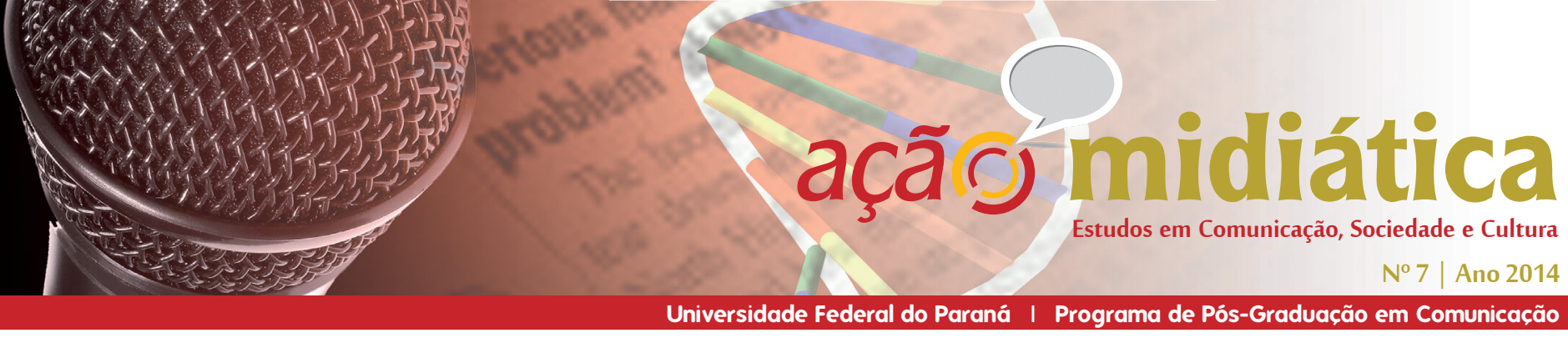

\title{
Por uma Perspectiva Culturalista nos Estudos de Comunicação ${ }^{1}$
}

For a Culturalist Perspective on Communication Studies

Por una Perspectiva Culturalista en los Estudios de Comunicación

Humberto da Cunha Alves de SOUZA²

BAUMAN, Zygmunt. A cultura no mundo líquido moderno. Trad. Carlos Alberto Medeiros. 1. ed. Rio de Janeiro: Zahar, 2013.

Bauman explora, nessa obra, como o conceito de cultura assumiu diferentes "missões" desde sua interpretação mais original a serviço das elites culturais, até estar a serviço da sedução na sociedade de consumo - período que o autor chama de modernidade líquida. É preciso lembrar que esse período é tratado por outros autores como pós-modernidade, modernidade tardia, hipermodernidade; metáforas que, como justificou o próprio Bauman, não é seu objetivo debater. O que chama atenção é a linguagem complexa do autor, característica que se identifica na leitura de outras obras. Exige-se, portanto, profunda atenção do leitor; bem como seu conhecimento prévio de que Bauman é um estudioso cuidadoso da "sociedade de consumo", conceito muito presente em suas obras.

É importante dizer que Bauman é um dos mais influentes pensadores da atualidade. Sociólogo, nascido em Poznań, na Polônia, em 1925, vive na Inglaterra desde 1971, onde iniciou a carreira de professor na Universidade de Leeds. Atualmente é professor emérito de sociologia das Universidades de Leeds e Varsóvia. Tem cerca de trinta livros publicados no Brasil pela editora Zahar, mas, no total, são 57 livros e mais de cem artigos publicados. Foi homenageado com os prêmios Amalfi Europeia de Sociologia e Ciências Sociais, em 1992; Theodor W. Adorno, em 1998; e Príncipe de Astúrias de Comunicação e Humanidades, em 2010. Também em 2010, a Universidade de Leeds lançou o Instituto Bauman, em sua honra. Zygmunt Bauman é considerado o grande pensador da modernidade, inclusive em sua fase atual, a qual chamou de modernidade líquida. Dedica-se, ainda, a pensar temas contemporâneos como a globalização, o consumismo e a moralidade.

Essa obra está dividida em seis capítulos, a saber: 1) Apontamentos sobre as peregrinações históricas do conceito de "cultura"; 2) Sobre moda, identidade líquida e utopia nos dias atuais: algumas tendências culturais do século XXI; 3) Cultura: da construção da nação

1 Resenha apresentada à sétima edição da Revista Ação Midiática - Estudos em Comunicação, Sociedade e Cultura, publicação ligada ao Programa de Pós-Graduação em Comunicação, da Universidade Federal do Paraná.

2 Mestrando em Comunicação pela UFPR. Graduado em Comunicação Social, com habilitação em Publicidade, Propaganda e Marketing pelo UNINTER (2011).E-mail: hu.souza@gmail.com 
ao mundo globalizado; 4) A cultura num mundo de diásporas; 5) A cultura numa Europa em processo de unificação e; 6) A cultura entre o Estado e o mercado.

No primeiro capítulo, Bauman traça um interessante percurso histórico do conceito de cultura que começa em sua interpretação mais original (onde a cultura recebeu uma missão proselitista, a serviço de refinar o costume dos povos); passando para a modernidade (que a coloca a serviço de um projeto iluminista; uma ferramenta básica da construção de uma nação, de um Estado e de um Estado-nação e, logo em seguida, da manutenção desse sistema); chegando, por fim, à modernidade líquida (onde a cultura é modelada para atender a necessidades individuais). Em tempos líquido-modernos "a cultura consiste em ofertas e não em proibições", ela está empenhada em "seduzir" e não mais em "esclarecer os povos". "Em suma, a cultura da modernidade líquida não tem um 'populacho' a ser esclarecido e dignificado; tem, contudo, clientes a seduzir", assinala Bauman (2013, p. 18-21).

Exemplificando a função de sedução da cultura, Bauman traz em seu segundo capítulo o caso da moda e das identidades líquidas. A moda, para o pensador, serve como força capaz de gerar um movimento e, ao mesmo tempo, transforma-se em energia capaz de contrapor esse mesmo movimento. Isto é, essa contradição está no fato de que ao mesmo tempo, por meio da moda, espera-se o reconhecimento em um grupo e se pretende distinguir-se, ser original. Nesse contexto, o "modelo pessoal da busca de identidade torna-se o camaleão" ou o modelo da figura mitológica de Prometeu (BAUMAN, 2013, p. 28). A perda de individualidade, portanto, pode vir como efeito contrário ao pretendido. "A moda coloca todo estilo de vida em estado de permanente e interminável revolução" (BAUMAN, 2013, p. 26).

Em seu terceiro capítulo, o pesquisador argumenta como o processo da globalização está presente nas características da migração cultural. Divide-a em três fases: 1) fase da emigração de 60 milhões da Europa para "terras vagas". O que restasse da população nativa se tornaria outro caso de "cultivo"; 2) fase do giro de 180 graus, em que a população nativa (com vários graus de "educação") acompanharia os colonizadores em seu retorno à terra natal. Nessa fase ocorreu o surgimento das minorias, ainda "carentes" da missão proselitista e das cruzadas culturais e; 3 ) a terceira e última fase, ainda em pleno curso, que introduz a era das diásporas, uma era de cidadania e de lealdade dual ou múltipla, sem fronteiras para a migração ou a emigração.

Bauman então explora com detalhes a fase de diásporas no quarto capítulo. De específico, traz o argumento de que o "multiculturalismo" acaba agindo como uma força conservadora, pois permite que diferentes culturas coexistam, mas não torna prazerosa a convivência entre elas. $\mathrm{O}$ exemplo de Charles Taylor sobre Quebec, cidade em que os habitantes são obrigados a enviar os filhos para escolas francófonas, independente da vontade dos membros da sociedade naquele momento, reforça esse argumento. Se, de um lado há o direito da comunidade de preservar 
sua cultura, de outro está o direito do indivíduo em defender-se das imposições culturais da comunidade. Um sentimento de segurança "dos dois lados do muro" seria a condição para o diálogo entre culturas, diz o autor.

No quinto capítulo, questões já assinaladas referentes a minorias e ao processo de formação do Estado-nação são retomadas, dessa vez com detalhes específicos sobre o contexto da Europa. Para o sociólogo, a Europa é o lugar onde mais se convive com a presença de um "Outro", o que obriga os europeus a negociarem condições de coabitação, apesar das diferenças. Nesse ponto, Bauman introduz a questão dos direitos humanos. A diferença encontrada entre as culturas deve ser "bastante distinta" para que se considere demandá-la como um direito humano. Com isso, esta terceira fase das diásporas - ainda em pleno curso - requer coabitação pacífica, argumenta ele.

Seu sexto e último capítulo explora as forças do Estado e do mercado sob a cultura. A despeito das mudanças no regime de Estado (França no período entre 1815 e 1875) a cultura manteve-se, com o patrocínio do Estado, desde sempre, próxima à sua missão proselitista de refinar o gosto cultural dos povos. Já para a força do mercado, preocupado com os critérios do consumo, a cultura se torna um objeto para a satisfação de necessidades individuais. Nesse caso, a tentação está em oferecer a promessa de que as pessoas sentirão necessidade de consumir aquilo que os artistas criarem; por outro lado, a força do mercado acabará por determinar a demanda e definir o que deve ser considerado arte e, portanto, um "bom negócio". Nada resta à arte além de conviver com esse paradoxo.

Bauman conclui seu livro com uma observação que, na sequência, é necessário questionar. Diz o autor que o verdadeiro significado da arte contemporânea (e, com efeito, seu papel na cultura) surge no encontro íntimo entre o público (aquele que irá significar) e a obra de arte (aquilo que será significado, ainda não consciente de seu potencial). Um "Estado cultural" tem como missão, portanto, promover o encontro frutífero entre público e obra de arte. É nesse tipo de encontro que a arte é concebida e realizada. É esse encontro local, "face a face", que precisa ser estimulado; que aguarda o patrocínio de um Estado contemporâneo, para o autor.

Parece arriscado, logo no fim do livro, assim, sem tempo de explorar adequadamente a questão, dizer que o verdadeiro significado da arte só ocorre no "momento mágico" do "face a face", ainda mais em tempos contemporâneos, em que tecnologias (digitais ou não) estão presentes nas práticas e nos processos de comunicação humana e, igualmente, de seu processo de significação da realidade, da arte e de seus efeitos na cultura. O receio, aqui, é que esse argumento sustente uma exclusão das artes digitais daquilo que é ou que será considerado como arte; pensadas e criadas para a experiência mediada por tecnologias digitais, sob esse argumento, e invocadas sob uma análise mais conservadora, a ausência do tal momento mágico do face a face "deslegitimaria" as artes digitais. Evidentemente, fala-se, aqui, sobre o momento 
da experiência e não da criação artística.

A controvérsia anteriormente apontada foi necessária para, inclusive, defender a relevância do conteúdo da obra aqui resenhada. A perspectiva histórica cultural apresentada nesse livro é de importância substancial para reflexões de perspectiva culturalista nos estudos de comunicação. É dizer que, se por um lado Bauman alertou que no percurso histórico do conceito de cultura houve um tempo de missão proselitista, é possível dizer que essa missão parece voltar de tempos em tempos, se é que realmente alguma vez foi superada. Ora, a conclusão final de Bauman parece cair nessa armadilha ao sugerir o momento mágico da arte como sendo apenas aquele que ocorre no encontro "face a face", negando à arte a dimensão da experiência que também ocorre via tecnologias, por exemplo. Fica o alerta, portanto, para que sua obra não perca a importância a qual se anunciou desde o primeiro parágrafo.

Provocação à parte, cabe relembrar a "solução" encontrada por Bauman no terceiro capítulo: no "mundo das diásporas" um sentimento de segurança seria a garantia para o diálogo entre as diferentes culturas e, quem sabe, o caminho mais curto para a coabitação pacífica. Contudo, em entrevista ao Instituto CPFL Cultura, em 2011, Bauman avaliou a sociedade contemporânea - diante do que chamou por "ambivalência da vida" - sob dois valores essenciais: segurança e liberdade. Na ocasião, sugeriu que o homem não pode viver na ausência de um deles, nem sem seu equilíbrio. "Segurança sem liberdade é escravidão. Liberdade sem segurança é um completo caos" (BAUMAN, 2011). Em suas palavras: "o problema é que ninguém ainda, na história, e no planeta, encontrou a fórmula de ouro, a mistura perfeita de segurança e liberdade" (BAUMAN, 2011). Ou seja, teria Bauman encontrado a mistura perfeita que o levasse a sugerir, sem grande preocupação, uma "pitada" a mais de segurança? Não é próprio da "era das diásporas" o convívio contraditório entre segurança (necessidades comunais/nacionais) e liberdade (necessidades individuais)? Nesse ponto, algumas das afirmações de Bauman poderiam ser mais claras; didáticas até, se for o caso. Não custa lembrar o aviso no início desta resenha: exige-se, portanto, profunda atenção do leitor.

Antes de encerrar, outra reflexão merece ser compartilhada. Não é a concepção original de cultura (como instrumento de evolução social, de refinamento dos costumes, para se levar "cultura" aos povos), em última análise, que parece ter sido a condicionante das utopias nos estudos iniciais da cibercultura? Anunciava-se (com destemido determinismo tecnológico) um novo mundo de possibilidades infinitas, de resistência ao capitalismo, de emergência e de aperfeiçoamento da democracia e das cidades. Uma "nova cultura" capaz de livrar o povo de seu estado de barbárie, de levar cultura para todos diante das telas, e, finalmente, formar indivíduos éticos por meio de uma educação libertadora propiciada pelas novas tecnologias da comunicação. Ora, qual é o saldo após os "anos dourados" da cibercultura? Tal qual questionou Alex Primo (2013, p. 13-14): “A grande indústria midiática de fato capitulou diante da cultura 
